\title{
In vitro morphogenetic responses from obligatory apomictic Taraxacum belorussicum Val. N. Tikhom seedlings explants
}

\author{
Adrianna Gałuszka ${ }^{1} \cdot$ Maciej Gustab $^{2} \cdot$ Monika Tuleja $^{2}$ (D)
}

Received: 31 March 2019 / Accepted: 5 September 2019 / Published online: 13 September 2019

(c) The Author(s) 2019

\begin{abstract}
Taraxacum belorussicum Val. N. Tikhom, a poorly known and obligatory apomictic species, is an attractive plant material for studying the embryological, genetic and molecular mechanisms of apomixis. This work aims to obtain an efficient protocol for Taraxacum belorussicum regeneration. Four types of explants (cotyledons, hypocotyls, meristems and roots) that were taken from 2-weeks-old seedlings were used for in vitro cultures, and a fast and efficient protocol of T. belorussicum regeneration was obtained. Various $1 / 2$ MS-based media containing IAA $(5.71 \mu \mathrm{M})$, TDZ (4.54 $\mu \mathrm{M})$ and PSK $(100 \mathrm{nM})$ were chosen to assess the morphogenetic abilities of selected T. belorussicum explants. Studies on the role of PSK were done in three independent experiments, where the most significant factors were always light and darkness. All explants produced callus by the third day of culture and adventitious shoots after 7 days, although in an asynchronous indirect manner, and with different intensities for all explant types. The most preferred medium culture for hypocotyl, cotyledon and meristem explants was $1 / 2 \mathrm{MS}+\mathrm{TDZ}$, and $1 / 2 \mathrm{MS}+\mathrm{IAA}+\mathrm{TDZ}+\mathrm{PSK}$ for roots which were the only explant sensitive to PSK. A short darkness pretreatment (8 days) in PSK medium was found suitable to enhance organogenesis. Secondary organogenesis was observed for regenerated plants on meristem explants from the $1 / 2 \mathrm{MS}+\mathrm{IAA}+\mathrm{TDZ}+\mathrm{PSK}$ medium. A weak somatic embryogenesis was observed for hypocotyl and cotyledon explants from $1 / 2 \mathrm{MS}+\mathrm{IAA}+\mathrm{TDZ}$ and $1 / 2 \mathrm{MS}+\mathrm{IAA}+\mathrm{TDZ}+\mathrm{PSK}$ media. Histological and scanning electron microscope images (SEM) of $T$. belorussicum confirmed indirect organogenesis and somatic embryogenesis. Plant material treated with aniline blue solution revealed the presence of callose in the cell walls of cotyledon and hypocotyl explants. The presence of extracellular matrix (ECM) and heterogenic structure of callus was also verified by scanning electron microscopy and light microscopy, confirming the high morphogenetic ability of $T$. belorussicum .
\end{abstract}

\section{Key message}

An efficient regeneration protocol for Taraxacum belorussicum, the obligatory apomict, was obtained. Application of PSK revealed the significance of light and darkness as a key factor in the morphogenetic response. A short darkness pretreatment (8 days) in PSK medium was found suitable to enhance organogenesis. Histological and scanning electron microscope images confirmed indirect organogenesis and somatic embryogenesis presence. The protocol can enhance the knowledge about this species in studying the embryological, genetic and molecular mechanisms of apomixis.

Communicated by Sergio J. Ochatt.

Electronic supplementary material The online version of this article (https://doi.org/10.1007/s11240-019-01694-4) contains supplementary material, which is available to authorized users.

Monika Tuleja

monika.tuleja@uj.edu.pl

1 Department of Clinical Immunology, Jagiellonian University

Medical College, Cracow, Poland

2 Department of Plant Cytology and Embryology, Institute of Botany, Jagiellonian University, Gronostajowa Street 9, 30-387, Cracow, Poland 
Keywords Taraxacum belorussicum · Apomixis · Phytosulfokine $\cdot$ Somatic embryogenesis $\cdot$ Organogenesis

$\begin{array}{ll}\text { Abbreviations } \\ \text { BAP } & \text { 6-Benzyl amino purine } \\ \text { ECM } & \text { Extracellular matrix } \\ \text { IAA } & \text { Indole-3-acetic acid } \\ \text { BA } & \text { Indole-3-butyric acid } \\ \text { MS } & \text { Murashige \& Skoog } \\ \text { NAA } & \text { Naphthalene acetic acid } \\ \text { PAS } & \text { Periodic acid schiff } \\ \text { PGRs } & \text { Plant growth regulators } \\ \text { PSK } & \text { Phytosulfokine } \\ \text { SE } & \text { Somatic embryogenesis } \\ \text { SEM } & \text { Scanning electron microscope } \\ \text { TDZ } & \text { Thidiazuron }\end{array}$

\section{Introduction}

Taraxacum belorussicum Val. N. Tikhom or dandelion, belongs to the genus Taraxacum (Asteraceae) (Tikhomirov 2003). This genus includes many species which were used for the analysis of embryological, genetic and molecular aspects of apomictic mechanisms (Janas et al. 2016). In general, dandelions have also been a part of the natural medicine tool kit because of their medical qualities as diuretic, choleric, anti-inflammatory, anti-oxidative, anti-carcinogenic and melliferous. T. belorussicum Val. is also a raw material for the cosmetic industry (Hu and Kitts 2003; Jamshieed et al. 2010). Based on their specific features and heavily urbanized areas of growth (Erofeeva 2014) some Taraxacum species can play a role as temperate climate bio-indicators (Jamshieed et al. 2010). T. belorussicum is a Palustria triploid species (Marciniuk et al. 2010) and comes from the area of Minsk in Belarus where it was described for the first time by Tikhomirov (Tikhomirov 2003). It is an obligatory apomict that can produce embryos in a parthenogenetic manner, and can thus be used for the comparative study of parthenogenesis and somatic embryogenesis.

Apomixis is a type of plant reproduction during which the embryo is formed without full meiosis and syngamia, or omitting either of these two processes (Noyes 2007). Taraxacum is characterized by the occurrence of diplospory apomixis (Koltunow 1993; Hand and Koltunow 2014), where a meiotic prophase is observed, but chromosomes do not create bivalents or metaphase tiles. Instead, a restitution nucleus is formed which leads to generation of unreduced embryo sac cells after successive mitotic divisions (Hand and Koltunow 2014; Rodkiewicz et al. 1996). Despite this, some apomictic species often maintain the ability to sexually reproduce, and certain seed parts have a zygotic origin (Rodkiewicz et al. 1996).
One of the common morphogenetic pathways leading to in vitro plant regeneration is organogenesis (Huang et al. 2014), which can be indirect via callus and direct by the creation of adventitious shoots from explant tissue (Woźny and Przybył 2004). A second possible path of in vitro morphogenesis is somatic embryogenesis, with somatic embryo induction from a somatic cell without fertilization (Williams and Maheswaran 1986). Somatic embryos can be formed directly from the initial explant (Kuo et al. 2005) or indirectly from callus cells (Jasrai et al. 2003). Both morphogenetic processes are under the control of several factors, one of which is the explant's origin (Ebida and Hu 1993), while others are the growth factors, the auxins, cytokinins and polysaccharides, amino acids, vitamins and proteins (NicCan et al. 2015) to which it is exposed. The ratio between concentration of auxins and cytokinins has a crucial influence on in vitro morphogenesis (Isah 2015). Phytosulfokine (PSK), which was isolated for the first time from the Asparagus officinalis mesophyll (Matsubayashi and Sakagami 1996), being a peptide hormone, plays a role of regulatory molecule in the growth and development of plant cells, especially in somatic embryogenesis induction (Lorbiecke et al. 2005; Igasaki et al. 2003; Kobayashi et al. 1999; Maćkowska et al. 2014; Ochatt et al. 2018).

Plant cell predisposition to undergo one of the two developmental pathways in vitro can be predicted using callose identification, as callose deposited in the cell walls is a marker of somatic embryogenesis. In addition, the presence of cuticle and the loss of plasmodesmata connections are attributed to this process (Fiuk and Rybczyński 2006). Callose may be also deposited in the place of damage as protection against microorganism infection (Ellinger and Voigt 2014).

According to the latest data, the presence of the Extracellular Matrix (ECM) in in vitro culture is a specific feature of morphogenesis or germinal tissues that is associated with ECM signaling functions. In some cases, ECM may perform a protective function or is seen as a specific feature of callus surfaces formed under in vitro conditions (PopielarskaKonieczna et al. 2013). The formation of ECM may be the result of stress factors or exposure to chemical agents that protect callus cells (Bevitori et al. 2013) and can create a pathway for receiving and transducing signals that determine the recognition and fate of cells, and the morphogenesis of plant.

Apomixis is a phenomenon in which embryos arise by bypassing the process of fertilization, as also observed in embryo formation from somatic tissue cultured in vitro. To what extent this similarity has its justification at the molecular or physiological level so far is not known and is an interesting research challenge, for which use of apomictic 
Taraxacum species seems to be the right choice. Therefore, tracing the morphogenetic abilities with the hope of obtaining an efficient somatic embryogenesis of this species is the first and necessary step for later comparative studies of these two developmental processes. Based on the growing evidence suggesting that PSK has impact on acquisition of SE and morphogenesis, while there are no reports concerning these processes in $T$. belorussicum, we have attempted to identify problems related to the development of an efficient regeneration system for selected types of explants in in vitro conditions that included histological and SEM analysis.

\section{Materials and methods}

\section{Plant material}

All experiments were performed with seeds of apomict T. belorussicum Val. N. Tikhom kindly received from Professor Jolanta Marciniuk (Institute of Biology, University of Natural Sciences and Humanities at Siedlce in Poland). All seeds were sterilized by immersion in $70 \%$ ethanol (Sigma, St. Louis, MO, USA) for $30 \mathrm{~s}$ and then in $2 \%$ solution of sodium hypochlorite (Sigma) for $15 \mathrm{~min}$. Next, they were rinsed three times in sterile water and placed in Petri dishes (Corning Incorporated, Corning, NY) containing $1 / 2$ MS (Murashige and Skoog 1962) medium supplemented with $30 \mathrm{~g} / \mathrm{l}$ sucrose and $8 \mathrm{~g} / \mathrm{l}$ agar.

\section{In vitro plant culture conditions}

All used media were based on MS medium (Murashige \& Skoog Medium, Duchefa Biochemie B.V., Haarlem, The Netherlands). Seeds were cultured onto $20 \mathrm{ml}$ of $1 / 2$ MS medium culture under a 16 -h light photoperiod (cool white fluorescent light with an intensity of $\left.39 \mu \mathrm{M} \times \mathrm{m}^{-2} \times \mathrm{s}^{-1}\right)$ at $23 \pm 2{ }^{\circ} \mathrm{C}$ for 2 weeks. Afterwards, four types of explants: cotyledon (Fig. S1b), meristem (Fig. S1c), hypocotyl (Fig. S1d) and root (Fig. S1e) were obtained from the 2-week-old seedlings (Fig. S1a) and cultured on several media according to different experimental systems with 25 explants per Petri dish, in three repetitions. As a control, $1 / 2$ MS medium was used.

Organogenesis model regenerated plants with clearly formed leaves were isolated from explants after 40 days of culture and transferred into test-tubes (Equimed, Cracow, Poland) containing $50 \mathrm{ml} 1 / 2 \mathrm{MS}$, supplemented with $4.92 \mu \mathrm{M}$ IBA, under conditions as above for 90 days without subculturing. Then, regenerated well rooted plantlets were transferred into pots filled with experimental soil media, covered by transparent plastic boxes and kept in the same culture conditions for the next 14 days. Within this time, all plantlets acclimatized successfully.

SE/PSK model/short darkness explants were cultured in $1 / 2 \mathrm{MS}$ medium supplemented with $5.71 \mu \mathrm{M}$ IAA, $4.54 \mu \mathrm{M}$ TDZ and $100 \mathrm{nM}$ PSK (phytosulfokine- $\alpha$, PeptaNova $\mathrm{GmbH}$, Germany) at $23 \pm 2{ }^{\circ} \mathrm{C}$ for 8 days in the dark (short darkness), then explants were transferred to the light regime above for 60 days, with two subcultures (Fig. S2). Next, the regenerated plants were test tube cultured (Equimed, Cracow, Poland) in $50 \mathrm{ml}^{1 / 2} \mathrm{MS}$, supplemented with $4.92 \mu \mathrm{M}$ IBA under the photoperiodic light and temperature conditions as above.

SE/PSK model/long darkness Explants were cultured in $1 / 2 \mathrm{MS}$ medium, supplemented with $5.71 \mu \mathrm{M}$ IAA, $4.54 \mu \mathrm{M}$ TDZ and $100 \mathrm{nM}$ PSK at $23 \pm 2{ }^{\circ} \mathrm{C}$ for 55 days in the dark (long darkness), and were then transferred to the light for 35 days without subculturing (Fig. S3). Six types of media were used in this experimental model (P1-1/2 MS - control, P2-1/2 MS + IAA + TDZ, P3-1/2 $\mathrm{MS}+\mathrm{IAA}+\mathrm{TDZ}+\mathrm{PSK}, \mathrm{P} 4-1 / 2 \mathrm{MS}+\mathrm{PSK}, \mathrm{P} 5-1 \frac{1}{2}$ MS + TDZ, P6-1/2 MS + TDZ + PSK). Next, the regenerated plants were test tube cultured in $50 \mathrm{ml} 1 / 2 \mathrm{MS}$, supplemented with $4.92 \mu \mathrm{M}$ IBA under the same photoperiodic light conditions as above at $23 \pm 2{ }^{\circ} \mathrm{C}$.

\section{Histological analysis of in vitro morphogenesis}

Samples of each kind of explant after 50 days of culture were fixed in a mixture of $5 \%$ glutaraldehyde in phosphate buffer, pH 7.2 (Sigma) in $5{ }^{\circ} \mathrm{C}$ overnight, washed four times in $0.1 \mathrm{M}$ phosphate buffer $(\mathrm{pH} 7.2)$, then dehydrated in an ethanol series $(10 \%, 30 \%, 50 \%, 70 \%, 96 \%$; 15 min each) and kept overnight in absolute ethanol. The fixed tissue samples were subsequently embedded in Technovit 7100 (Heraeus Kulzer, South Bend, Indiana, USA). Next, histology blocks of plant material were made using a solution of Technovit B under vacuum for $24 \mathrm{~h}$. Plant material histology blocks slices (7 $\mu \mathrm{m}$ of thickness) were obtained by using a rotational microtome-Microm HM 355 S I Microtome (MICROM International $\mathrm{GmbH}$, Walldorf, Germany).

Histological samples were stained using $0.1 \%$ toluidine blue (Sigma), $0.05 \%$ aniline blue (Sigma), $0.5 \%$ naphthol blue black (Sigma) and PAS—Periodic Acid Schiff (Sigma). Next, sample slides were closed by histological medium (Entellan; Merck Millipore, USA). To detect cell structures such as the cytoplasm or nuclear cell, the slides were first warmed, then stained with $0.1 \%$ toluidine blue for $30 \mathrm{~s}$ and afterwards, washed in distilled water. The callose fluorescence was observed in UV light (370 nm) after staining with $0.1 \%$ toluidine blue for $30 \mathrm{~s}$ and being incubated with $0.05 \%$ aniline blue for $10 \mathrm{~min}$. 


\section{Scanning electron microscope (SEM)}

For examination utilizing the scanning electron microscope, plant material of each type of explant was collected at the 50 th day of culture and pre-fixed in 5\% buffered glutaraldehyde (0.1 M phosphate buffer, $\mathrm{pH}$ 7.2) for $3 \mathrm{~h}$ at room temperature. After dehydration in a graded ethanol series, samples were dried at the critical point of $\mathrm{CO}_{2}$ by use of a Quorum Technologies E3000 (Quorum Technologies Ltd., Lewes, UK). Afterwards, samples were coated with finegrained gold using automated sputter coater Jeol JFC - 1100 E (JEOL, Peabody, MA, USA) for imaging via scanning electron microscope Jeol JSM 5410 (JEOL).

\section{Observation and documentation of results}

Images of in vitro cultures were made utilizing a Canon PC 1089 (Canon, Uxbridge, Middlesex, United Kingdom) connected to a binocular loupe Stemi SV 11 (Carl Zeiss Microscopy, Jena, Germany) at 7-day intervals. Symptoms of somatic embryogenesis were observed on selected types of explants, while organogenesis was scored as an average amount of shoots per explant for all types of explants, after 20 and 45 days of culture for SE/PSK model/short darkness and after 30 and 65 days of culture for SE/PSK model/long darkness. Regenerated plants and ex vitro culture evolution were documented by Canon PC 1089 (Canon, Uxbridge, Middlesex, United Kingdom). Histology samples were analyzed using a phase contrast microscope Nikon Eclipse E400 (Nikon Corporation, Tokyo, Japan) with Olympus 10x/0.25 (Olympus Corporation, Tokyo, Japan) and Olympus 40x/0.55 (Olympus Corporation) objective lenses. Samples stained with aniline blue were analyzed with an EX330-380 (Nikon Corporation) excitation filter. Images were processed by EOS Utility version 3 software (Canon).

\section{Statistics}

Statistical analyses were performed by One-way ANOVA test with Tukey test for multiple comparisons and test $t$ with using the PRISM GraphPad 6.01 software (GraphPad Software Inc., San Diego, California, USA). Results were expressed as mean \pm SEM per one explant for all types of explants. Statistical significance of differences between groups were considered at $\mathrm{p}$ values: $* \mathrm{p}<0.01,{ }^{*} \mathrm{p}<0.01$, $* * * \mathrm{p}<0.001, * * * * \mathrm{p}<0.0001$.

\section{Results}

\section{Induction and development of callus}

All types of explants (meristem, hypocotyl, cotyledon, root), after mechanical damage, produced callus at different efficiency rates after 3 days of culture in all experimental models (Fig. 1). Observation of root explants (Fig. 1a) showed that callus formation begins initially at the ends of explants, in the place of scalpel cutting (Fig. 1b). Next, the entire explant swells (Fig. 1c) and callus formation subsequently covers the whole or the most part of the explant surface (Fig. 1d). Indeed, $100 \%$ of the explants started overgrowing with callus after 8 days of culture. At this time all explants showed two callus types, non-morphogenetic (Fig. 1d) and morphogenetic (Fig. 1e). Morphogenetic callus was identified by the formation of adventitious shoots (Fig. 1f) - a trait that is not characteristic for non-morphogenetic callus. Observation of hypocotyl and root explants provided similar information about the callus formation and development, albeit with some important differences. Initially, the callus had a compact structure and was visible on one part of the explants (Fig. 1c). The callus color concentrated around various shades of green, while white and yellow colors were also noticed.

During the culture of selected T. belorussicum explants, the most advanced formation and development of callus was observed on root (Fig. 1 I) and hypocotyl (Fig. 1 II) explants. Meristem explants also produced callus, but in a moderate amount, while callus was formed with the slowest and the least efficiency on cotyledon explants. Callusing was most intensive in the experimental model with a complete medium: 1/2 MS + IAA + TDZ + PSK (Fig. 1). Explants cultured on the control medium did not produce callus (data not shown). Results obtained from other experimental models $(1 / 2 \mathrm{MS}+\mathrm{IAA}+\mathrm{TDZ}$ and $1 / 2 \mathrm{MS}+\mathrm{TDZ}+\mathrm{PSK})$ revealed a varied intensity of callusing as a phase preceding the induction of adventitious shoots, observed on hypocotyl and root explants (Fig. 1). The weakest development of callus was noted on cotyledon explants. The callus color was from light to dark green, as well as white, yellow and brown. Meristem, cotyledon and hypocotyl explants showed the greenest shades, thus the largest amount of chlorophyll in callus cells, while shades of brown were visible on root explants.

\section{Morphogenetic response of selected explants depending on plant growth regulators treatment}

The intensity of morphogenetic response (organogenesis) of selected types of explants was expressed as the average number of adventitious shoots produced during in vitro culture. The anecdotal presence of somatic embryogenesis did not allow for its proper quantification. 
Fig. 1 Two paths of callus development, indirect organogenesis and somatic embryogenesis (arrow) of T. belorussicum in in vitro culture: $\mathbf{I}$ the development of callus from the root explant, II the development of callus from hypocotyl explant and the first symptoms of somatic embryogenesis (marked as an oval structures); a-explant on the first day of culture, $b$ - beginning of callus formation on the cut edges of explant, c-swelling callus and visible changes in the explant (after 14 days of culture), dmorphogenetic structures after a few days of culture, e-explant overgrown with developing callus (60th day of root explant culture), f-adventitious shoots on root explant on the 80th day of culture and hypocotyl after 28 days (indirect organogenesis). Photos came from SE/PSK model/short darkness; explants were cultured on $1 / 2 \mathrm{MS}$ medium supplemented with $5.71 \mu \mathrm{M}$

IAA, $4.54 \mu \mathrm{M}$ TDZ and $100 \mathrm{nM}$ PSK. Scale $1 \mathrm{~mm}$

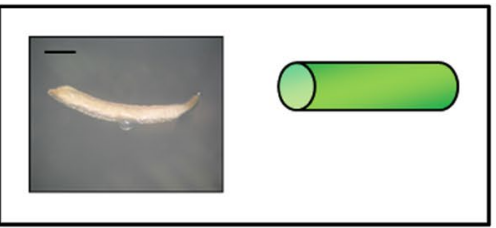

b

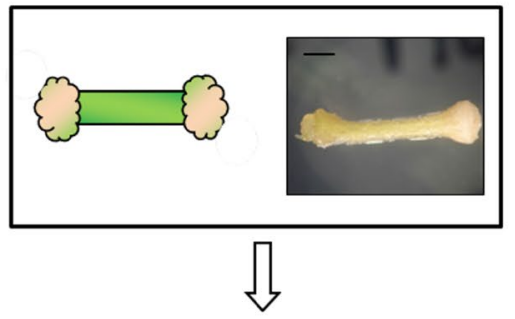

C

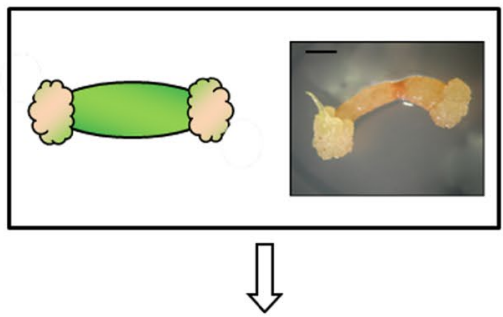

d
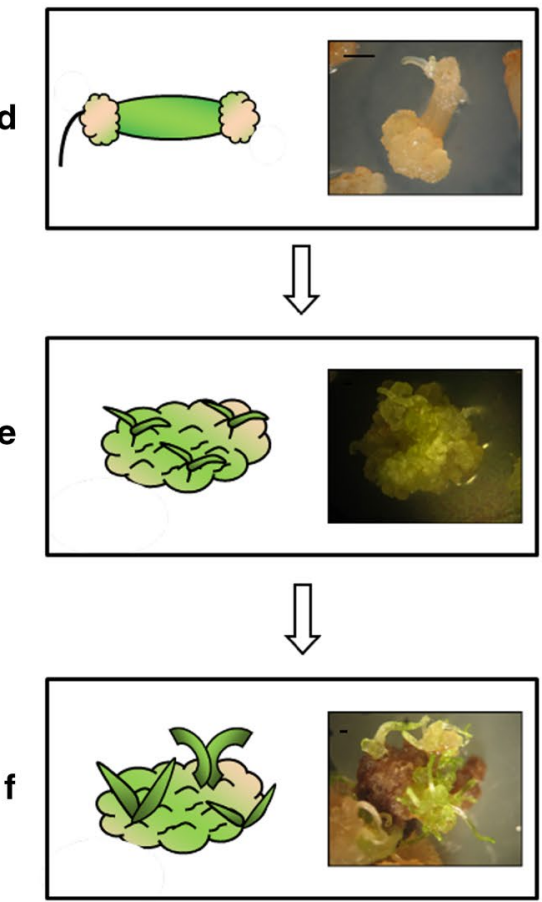

I
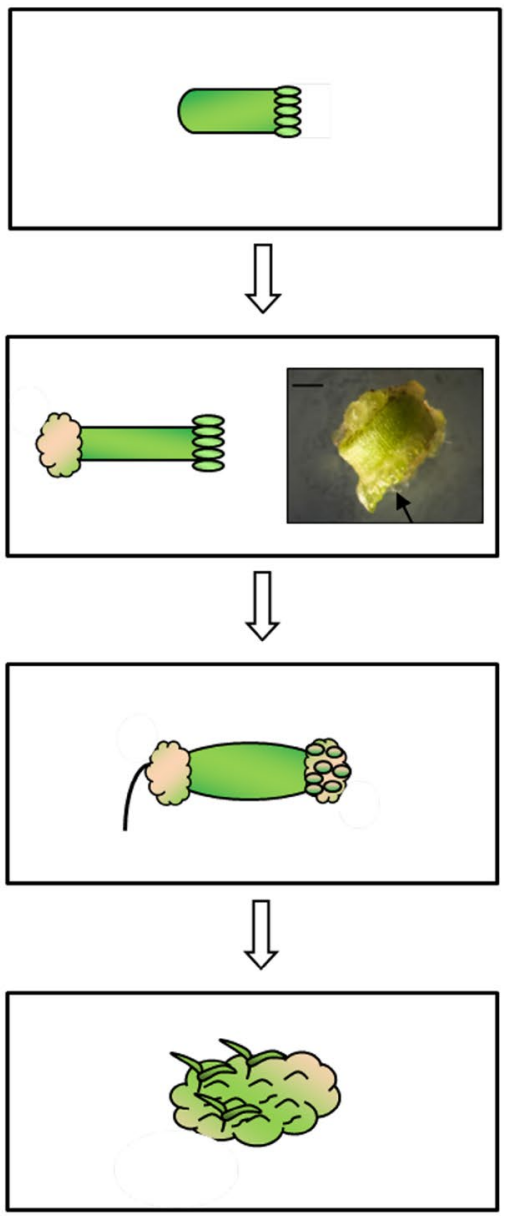

$\sqrt{1}$

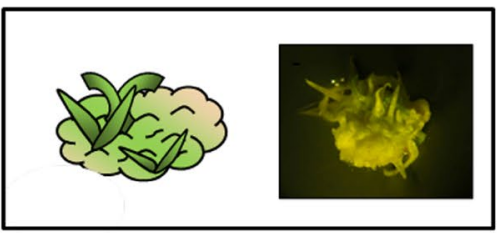

II

\section{Organogenesis}

In the organogenesis model, the first morphogenetic response occurred after 7 days of culture on $1 / 2 \mathrm{MS}$ medium with TDZ and IAA, where analyses revealed callus formation on all types of explants, but meristem and root explants degenerated over time. Furthermore, the presence of adventitious shoots was evident only on hypocotyl and meristem explant surfaces (Table S1). Hence, the regenerative efficiency in vitro was calculated only for these explants (Fig. 2a), with an average of regenerated plants of $8.48 \pm 1.7$ and $17.8 \pm 4.94$ for cotyledon and hypocotyl explants, respectively, whereby hypocotyl explants were selected for subsequent studies. Noteworthy, 140 out of 251 regenerated 
Fig. 2 Organogenesis efficiency of $T$. belorussicum explants. a hypocotyl and cotyledon after 40 days of culture on $1 / 2 \mathrm{MS}$ with $5.71 \mu \mathrm{M}$ IAA and $4.54 \mu \mathrm{M}$ TDZ. b hypocotyl, meristem, cotyledon and root cultured on $1 / 2 \mathrm{MS}$ with $5.71 \mu \mathrm{M}$ IAA, $4.54 \mu \mathrm{M}$ TDZ and $100 \mathrm{nM}$ PSK during 8 days without access to light and after the transfer of the explants to light for the subsequent 60 days. Number of adventitious shoots per one explant were assessed twice after 20 days (T1) and 45 days (T2) of culture. c hypocotyl, meristem, cotyledon and root cultured on: P1—1/2 MS (control), P2-1/2 MS + PSK, P3-1/2 MS + TDZ, P4-1/2 $\mathrm{MS}+\mathrm{IAA}+\mathrm{TDZ}, \mathrm{P} 5-1 / 2$ $\mathrm{MS}+\mathrm{TDZ}+\mathrm{PSK}, \mathrm{P} 6-1 / 2$ $\mathrm{MS}+\mathrm{IAA}+\mathrm{TDZ}+\mathrm{PSK}$ during 55 days without access to light and after transferring the explants to light for the subsequent 35 days. The number of adventitious shoots per one explant were assessed twice after 30 days (T1) and 65 days (T2) of culture. Data are presented as mean \pm SEM per one explant for all types of explants. Statistical significance of differences between groups were considered at $\mathrm{p}$ values: $* \mathrm{p}<0.1$, $* * \mathrm{p}<0.01, * * * \mathrm{p}<0.001$, $* * * * \mathrm{p}<0.0001$ (a test $t, \mathbf{b}$ and c one-way ANOVA test). The figures show the results from 25 independent explants per one Petri dish in three repetitions
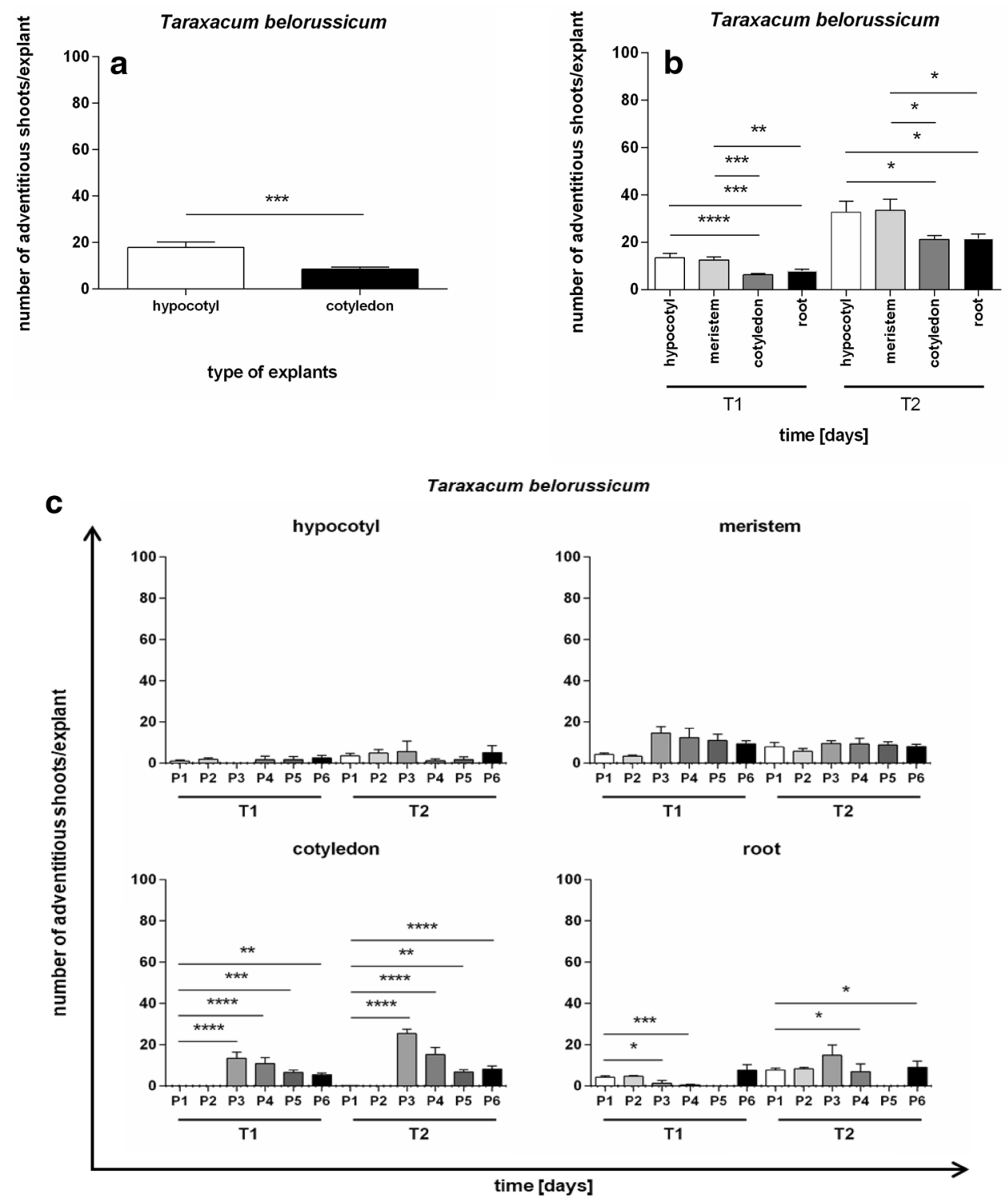

plants obtained from hypocotyl explants were successfully rooted and ultimately able to function in ex-vitro conditions.

In SE/PSK model/short darkness, hypocotyl and meristem explants revealed better morphogenetic response than did cotyledon and root explants after 20 and 45 days of culture on $1 / 2$ MS medium supplemented with IAA, TDZ and PSK, with a short time under dark conditions (8 days). The presence of adventitious shoots was observed on the surface of all type of explants and thus their regenerative efficiency was calculated. Analyses also showed that organogenesis efficiency in terms of average amount of regenerated plants was highest on meristem and hypocotyl explants, while that of root and cotyledon explants was the lowest (Fig. 2b). In addition, indirect organogenesis proceeded with different efficiency on the majority of all types of explants. However, all the regenerated plants obtained were successfully rooted after 28 days on $1 / 2$ MS medium supplemented with IBA.

In SE/PSK model/long darkness, meristem and cotyledon explants revealed better morphogenetic response than did hypocotyl and root explants after 30 and 65 days of culture under an extended period of time in dark conditions (55 days) (Fig. 2c). In this model, $1 / 2$ MS medium supplemented with TDZ turned out to be more efficient than medium with PSK added, for cotyledon, hypocotyl and meristem explants, while $1 / 2$ MS medium supplemented with IAA, TDZ and PSK showed the highest efficiency for root explants. Conversely, root explants cultured on $1 / 2 \mathrm{MS}$ medium with TDZ and PSK and cotyledon explants cultured on $1 / 2$ MS medium with PSK died out after 103 days of culture (Figs. 3 and 4). I was also observed that indirect organogenesis proceeded with diverse efficiency on the majority 


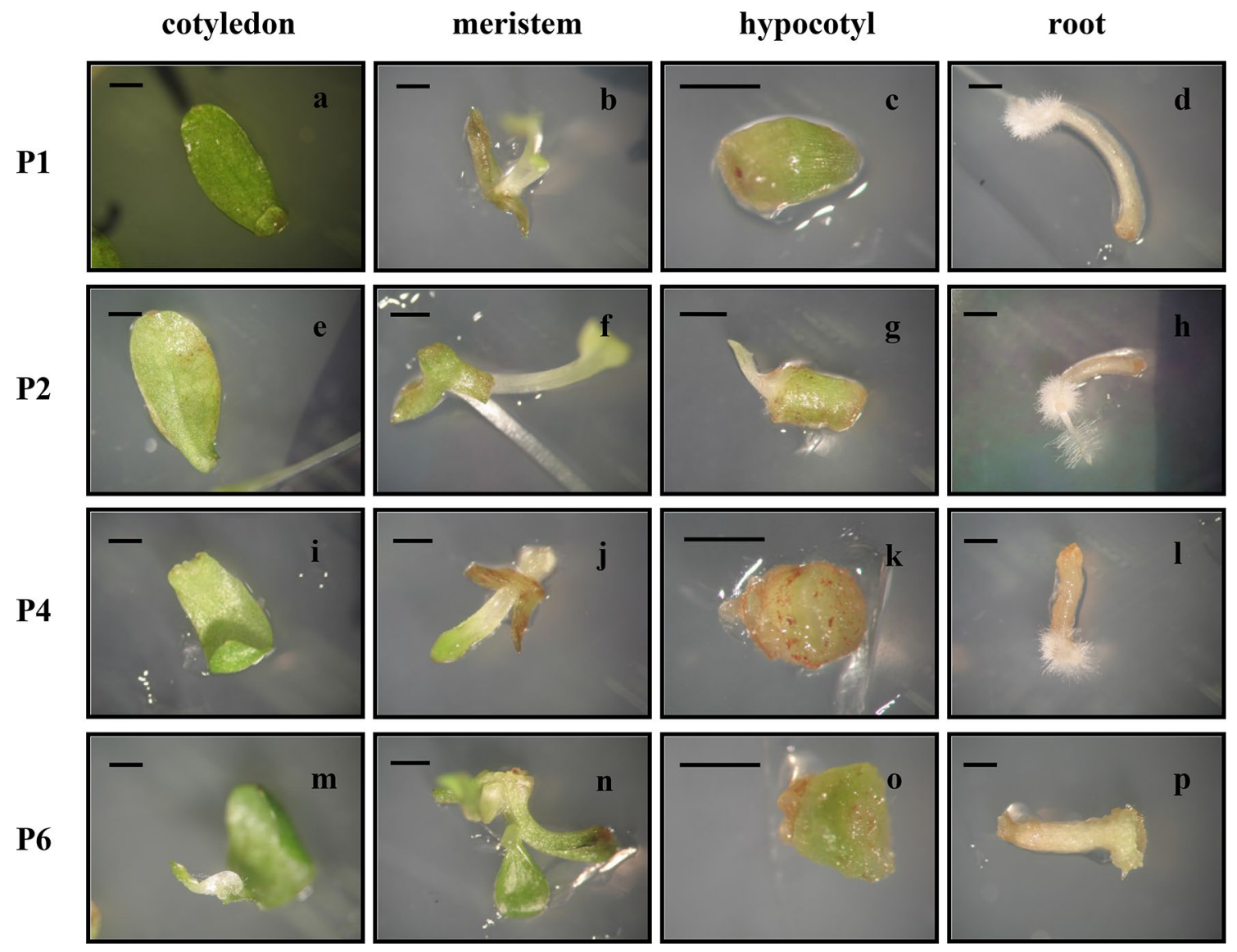

Fig. 3 The development of T. belorussicum explants (a, e, i, m cotyledon; $\mathbf{b}, \mathbf{f}, \mathbf{j}, \mathbf{n}$ meristem; $\mathbf{c}, \mathbf{g}, \mathbf{k}, \mathbf{o}$ hypocotyl; $\mathbf{d}, \mathbf{h}, \mathbf{l}, \mathbf{p}$ root) cultured on: $\mathrm{P} 1-^{1 / 2}$ MS (control), P2—1/2 MS + PSK, P4-1/2

of explants, while secondary organogenesis (adventitious shoots formation on the regenerated plants) was noticeable on regenerated plants from meristem explants cultured on $1 / 2$ MS medium supplemented with IAA, TDZ and PSK (Fig. 4n). All regenerated plants obtained were successfully rooted after 28 days on $1 / 2$ MS medium supplemented with IBA.

\section{Somatic embryogenesis}

In SE/PSK model/short darkness, symptoms of somatic embryogenesis were observed on hypocotyl and cotyledon explants (Fig. 1c II). Somatic embryos were formed directly from explant tissue cultured on all type of $1 / 2$ MS media supplemented with PSK. The highest efficiency of somatic embryogenesis, in the form of small, light-green globular structures, was observed on $1 / 2$ MS medium supplemented with TDZ, IAA and PSK with a short time period under darkness (8 days). Formation of somatic embryos was not observed in the organogenesis model and SE/PSK model/
$\mathrm{MS}+\mathrm{IAA}+\mathrm{TDZ}, \mathrm{P} 6-1 / 2 \mathrm{MS}+\mathrm{IAA}+\mathrm{TDZ}+\mathrm{PSK}$ in $23 \pm 2{ }^{\circ} \mathrm{C}$ after 7 days of culture (SE/PSK model/short darkness). Scale: $1 \mathrm{~mm}$

long darkness on all types of explants and in SE/PSK model/ short darkness on meristem and root explants.

\section{Role of phytosulfokine (PSK) in the process of organogenesis}

The applied conditions in SE/PSK model/short darkness were designed to enhance PSK activity by pre-incubation of explant cultures in the dark for 8 days. Results obtained clearly indicate that the addition of PSK to the medium increased the intensity and efficiency of the organogenesis process. However, the explants were in a poor condition: part of them began to quickly degenerate and, under these conditions, most explants were overgrown with callus (especially the root explants). To improve this, explants were subjected to light after 8 days of incubation in dark. During culture under light conditions, a significant improvement was evident, the color of explants changing from brown yellow to bright and dark green.

The combination of PSK with auxins and cytokinins enhanced the process of indirect organogenesis and had 


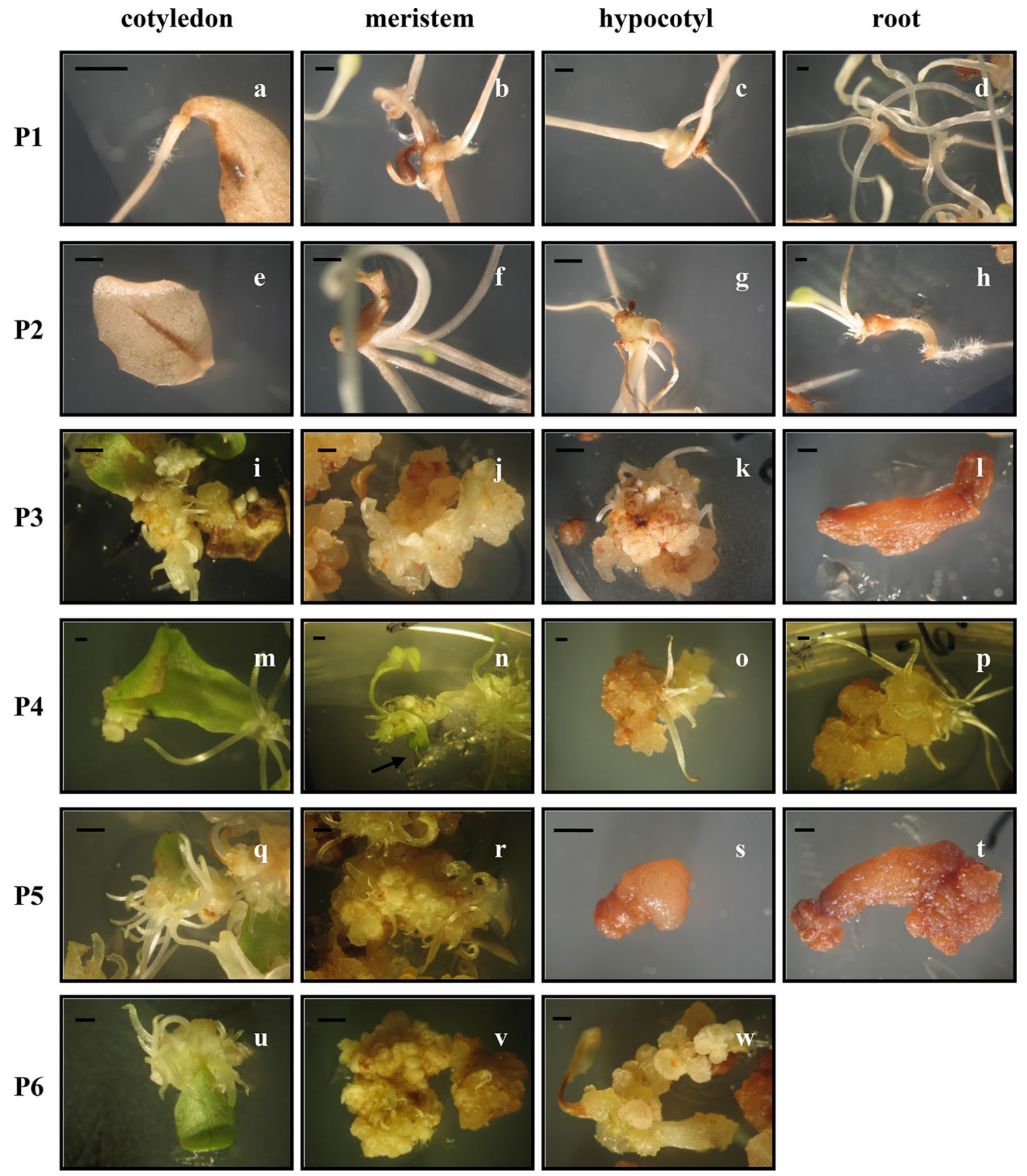

Fig. 4 The development of T. belorussicum explants (a, e, i, m, q, $\mathbf{u}$ cotyledon; $\mathbf{b}, \mathbf{f}, \mathbf{j}, \mathbf{n}, \mathbf{r}, \mathbf{v}$ meristem; $\mathbf{c}, \mathbf{g}, \mathbf{k}, \mathbf{o}, \mathbf{s}, \mathbf{w}$ hypocotyl; $\mathbf{d}$, $\mathbf{h}, \mathbf{l}, \mathbf{p}, \mathbf{t}$ root) cultured on: P1-1/2 MS (control), P2-1/2 MS + PSK,

a positive influence on somatic embryogenesis induction. Results obtained from SE/PSK model/long darkness with an extended period of explant culture in the dark (55 days), indicated that selected types of explants had undergone a varied intensity of morphogenesis process depending on the medium used (Fig. 2c). For cotyledon, hypocotyl and meristem explants, the use of a medium without PSK was much more favorable. However, root explants developed better on
$\mathrm{P} 3-1 / 2 \mathrm{MS}+\mathrm{IAA}+\mathrm{TDZ}, \mathrm{P} 4-1 \frac{1}{2} \mathrm{MS}+\mathrm{IAA}+\mathrm{TDZ}+\mathrm{PSK}, \mathrm{P} 5-1 / 2$ $\mathrm{MS}+\mathrm{TDZ}, \mathrm{P} 6-1 / 2 \mathrm{MS}+\mathrm{TDZ}+\mathrm{PSK}$ in $23 \pm 2{ }^{\circ} \mathrm{C}$ after 28 days of culture (SE/PSK model/long darkness). Scale: $1 \mathrm{~mm}$

a medium with PSK. It should be noted that the used media differed not only in the presence or absence of PSK, but also in the auxin and cytokinins content. Still, the interaction between PSK, auxins and cytokinins did not significantly affect the development of explants. In the case of hypocotyl, meristem and root explants, the use of PSK without 

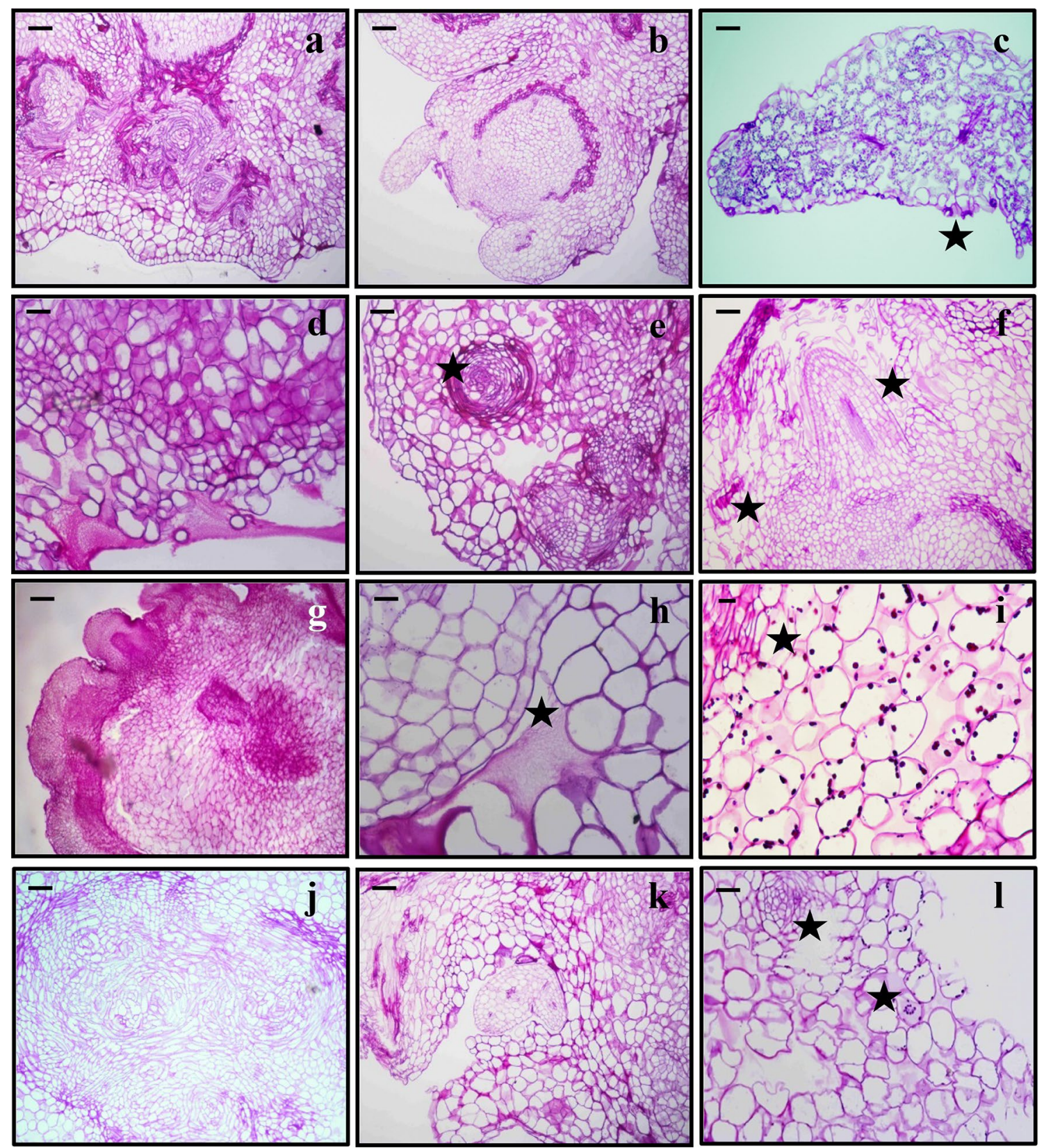

Fig. 5 Cross-section of $T$. belorussicum explants from SE/PSK model/long darkness: cotyledon (a, b), meristem (d, e), hypocotyl $(\mathbf{g}, \mathbf{h})$ and root $(\mathbf{j}, \mathbf{k})$ cultured on $1 / 2$ MS medium supplemented with $5.71 \mu \mathrm{M}$ IAA, $4.54 \mu \mathrm{M}$ TDZ and $100 \mathrm{nM}$ PSK in $23 \pm 2{ }^{\circ} \mathrm{C}$ after 55 days of culture: a explant with xylogenic centers, $\mathbf{b}$ somatic embryo from the cotyledon explant, $\mathbf{d}$ presence of ECM between cells of the meristem explant, e xylogenic centers (asterisk) in meristem explant, $\mathbf{g}$ morphogenesis on the edges of the explant, $\mathbf{h}$ ECM between hypocotyl cells with fragment of regenerated plant, $\mathbf{j}$ adventitious shoots as deformed relicts in the root explants, $\mathbf{k}$ cross-section through the explant tissue in advanced culture and leaf of regenerated plant, and cross-section of T. belorussicum explants from the organo- genesis model: cotyledon (c), meristem (f), hypocotyl (i) and root (l) cultured on $1 / 2 \mathrm{MS}$ medium supplemented with $5.71 \mu \mathrm{M}$ IAA and $4.54 \mu \mathrm{M}$ TDZ in $23 \pm 2{ }^{\circ} \mathrm{C}$ after 47 days of culture: $\mathbf{c}$ leaf of regenerated plant with fragment of the vascular bundle, stomata (asterisk) and starch grains in the mesophyll cells, $\mathbf{f}$ young stage of regenerating leaf (asterisk) with vascular bundle inside and the xylogenic center (asterisk), $\mathbf{i}$ numerous starch grains in callus cells and the xylogenic center at the young stage of its development (asterisk), l varied shape of callus cells, presence of ECM (asterisk) and xylogenic centers (asterisk) at the early stage of formation. PAS reaction. Scale: $100 \mu \mathrm{m}$ $(\mathbf{a}-\mathbf{g}, \mathbf{j}, \mathbf{k}), 25 \mu \mathrm{m}(\mathbf{h}, \mathbf{i}$ and $\mathbf{l})$ 

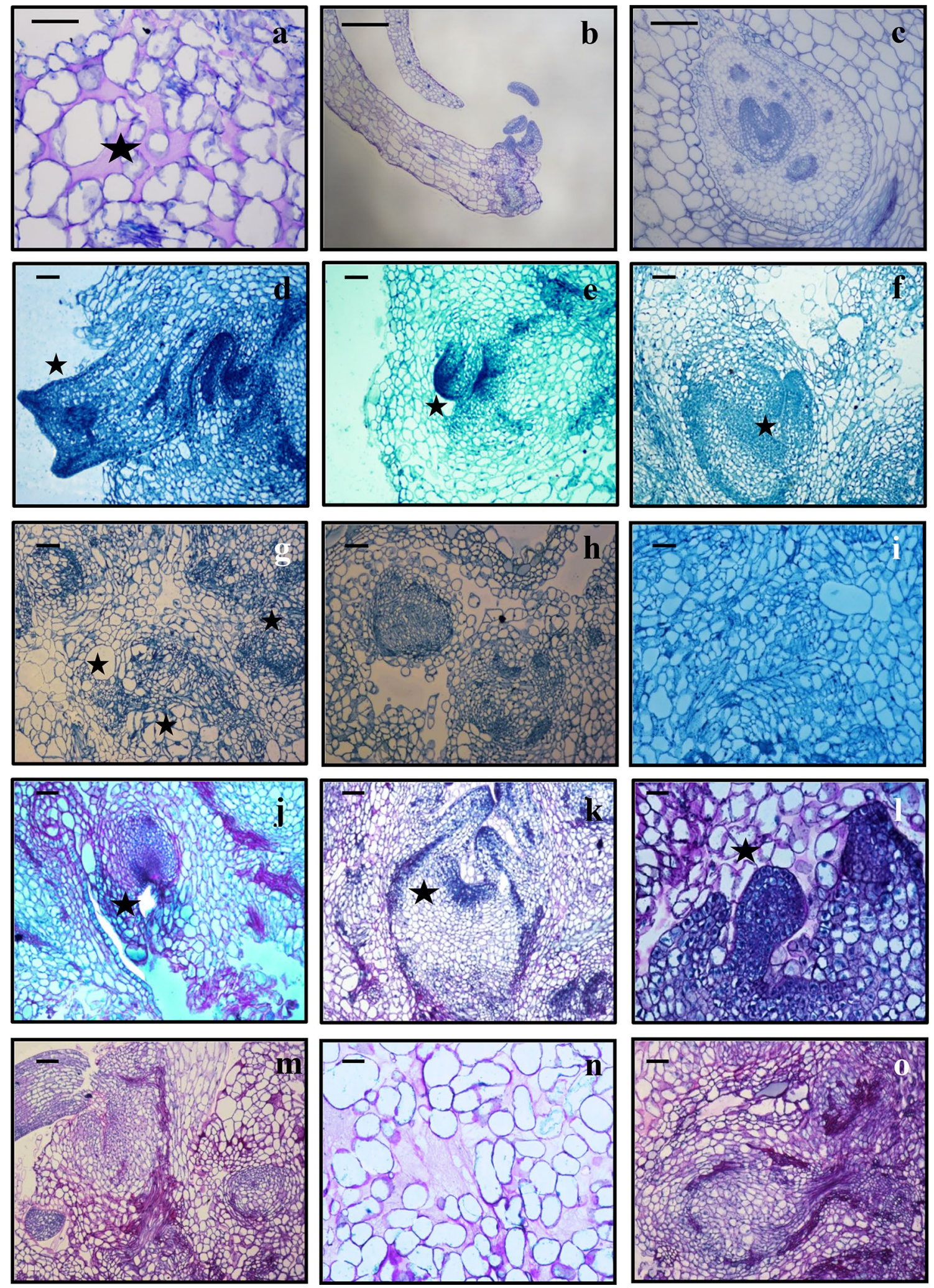

other agents, slightly stimulated the organogenesis process. However, in the case of cotyledon explants, the use of PSK without auxins and cytokinins did not bring a desired effect.
The applied light conditions in SE/PSK model/long darkness were also designed to enhance PSK activity. After 55 days, explants showed a poor condition, most of them 
४Fig. 6 Cross-section of T. belorussicum explants cultured on $1 / 2 \mathrm{MS}$ medium supplemented with $5.71 \mu \mathrm{M}$ IAA and $4.54 \mu \mathrm{M}$ TDZ from the organogenesis model: meristem $(\mathbf{a}, \mathbf{e}, \mathbf{j})$, cotyledon $(\mathbf{d})$, hypocotyl (f, k) and root (l) after 47 days of culture, and cross-section of $T$. belorussicum explants cultured on $1 / 2$ MS medium supplemented with $5.71 \mu \mathrm{M}$ IAA, $4.54 \mu \mathrm{M}$ TDZ and $100 \mathrm{nM}$ PSK: cotyledon (b) and meristem (c) after 20 days of culture from SE/PSK model/short darkness, meristem (G), hypocotyl $(\mathrm{H}, \mathrm{M})$ and root (I, N, O) after 55 days of culture from SE/PSK model/long darkness. b fibrous structure of ECM (asterisk) between callus cells and xylogenic centers, b, c organogenesis on the 20th day of culture at one of the poles, $\mathbf{d}$ regenerated plant (asterisk) growing from cotyledon explant and secondary meristematic center, e regenerated plant (asterisk) growing from the sub-surface layer of the meristem explant with meristematic center and one leaf, as well as an xylogenic center on the right, $\mathbf{f}$ regenerated plant from hypocotyl explant, meristematic center (asterisk), two growing leaves and arch of the vascular tissue, $\mathbf{g}$ cytological differentiation within the meristem, $\mathbf{h}$ secondary meristematic and xylogenic centers, $\mathbf{i}$ compact structure of explant with the varied shape of cells, $\mathbf{j}$ young adventitious shoot, content of protein and the rest of explant epidermis, $\mathbf{k}$ regenerated plant, apical meristem, two growing leaves and vascular bundles, $\mathbf{I}$ different shapes of regenerated young leaves, $\mathbf{m}$ enlargement of the fragment from which adventitious shoot grow, meristematic and xylogenic centers (asterisks), vascular bundles, $\mathbf{n}$ ECM between callus cells, o morphogenesis from pericycle. a-c Staining by $0.1 \%$ toluidine blue. Scale: $100 \mu \mathrm{m}(\mathbf{a}-\mathbf{c}) ; \mathbf{d}-\mathbf{i}$ Protein localization by staining with $0.5 \%$ naphthol blue black. Scale: $100 \mu \mathrm{m}$ $(\mathbf{d}-\mathbf{h}), 500 \mu \mathrm{m}(\mathbf{i}) ; \mathbf{j}-\mathbf{0}$ PAS reaction for the presence of starch in explants and staining with $0.5 \%$ naphthol blue/black to determine the protein localization. Scale: $25 \mu \mathrm{m}(\mathbf{n}), 100 \mu \mathrm{m}(\mathbf{k}-\mathbf{o}), 500 \mu \mathrm{m}(\mathbf{j}, \mathbf{l})$

began to die. So, all surviving cultures were transferred to the light for the subsequent 35 days. However, the effect of PSK on the formation of callus was noticed while under dark conditions. Observation of explants in the light showed a significant improvement in their condition as they turned from brown yellow to green (due to the restoration of chlorophyll). PSK had a positive effect on somatic embryogenesis (visible on cotyledon explants), but deformed somatic embryos (which were not able to convert) were observed. Such tissues did not produce regenerated plants and the culture was terminated at this stage.

\section{Histological evaluation of selected explants}

Explants from the organogenesis model and SE/PSK model/ long darkness were selected for histological analysis.

In the organogenesis model, histological analysis confirmed the presence of two types of callus tissue. This differed in the shape and size of cells. The first consisted of loosely distributed cells with various shapes and intercellular spaces (Fig. 5l). The second type was distinguished by a compact structure with meristematic centers and adventitious shoots were formed (Fig. 6e). These centers were mainly present in the subsurface layers, hence confirming that organogenesis proceeded indirectly via callus tissue. Cells in the meristematic centers were characterized by a dense cytoplasm, clearly visible nuclei and thin cell walls. In addition, to the adventitious shoots, somatic embryo-like structures were observed on the hypocotyl explants. Moreover, in some explants, different stages of regeneration process were observed at the same time of culture (Fig. 6d, e, k). Analyses also documented non-synchronized development of regenerated plants leaves from the meristem explants (Fig. 61). Still, explants maintained tissue integrity-made evident by the presence of anticlinal cell divisions in the epidermis of meristem explants (Fig. 6j). However, the majority of callus cells were highly vacuolated, in some cases, nuclei with well-visible nucleoli could be observed, as well as various cytokinesis phases. Xylogenic centers were also commonly present among the explants and callus cells (Figs. 5f, i, 1, 6a). Vascular tissue was observed in the adventitious shoots at advanced stages of regeneration (Figs. 5f, 6d) and in the root explants as deformed relicts (Fig. 5j). PAS staining showed, in all types of explants, the presence of starch granules accumulating around the meristematic centers, near the cell walls, mainly in the callus cells (Fig. 5i, 1). These granules were also quite noticeable in the stomates and the mesophyll tissue of regenerated leaves, as well as in the vascular tissue. This suggests a properly functioning photosynthetic system has developed (Fig. 5c). Their protein content was identified through naphthol blue black staining. The aforementioned granules were highly concentrated in the cells of meristematic centers, at various stages of development (Fig. 6d-f, j-1). Both PAS and toluidine blue staining revealed the presence of an extracellular matrix (ECM) with fibrous, reticular or mucoid structures filling the spaces between the callus cells (Fig. 6a). In contrast to the successful application of these two methods of staining, the ECM was not visible under naphthol blue/ black conditions, which makes evident its polysaccharide and non-protein character.

In the SE/PSK model/long darkness, histological analysis of the cotyledon explants confirmed indirect organogenesis and the induction of indirect somatic embryogenesis (Fig. 5a, b). Results revealed structures similar to somatic embryos formed from explant tissues overgrown with endogenous callus (Fig. 6b). These structures were deformed at the later stage of development. The PAS staining showed clearly visible vascular bundles in the embryo cotyledon explant and the absence of starch in explant and embryo tissues (Fig. 5b). Secondary xylogenic centers were seen within the mesophyll, the explant epidermis was noted to be continual (Fig. 5a) and lobed nuclei cells were noted in explant tissues and regenerated plants. Naphthol blue/black staining showed a concentration of the dye in the cells of the developing regenerated plant, in the top region of explant. This effect may indicate formation of the apical meristem. Double staining with PAS and naphthol blue/black revealed the presence of secondary meristematic centers next to 

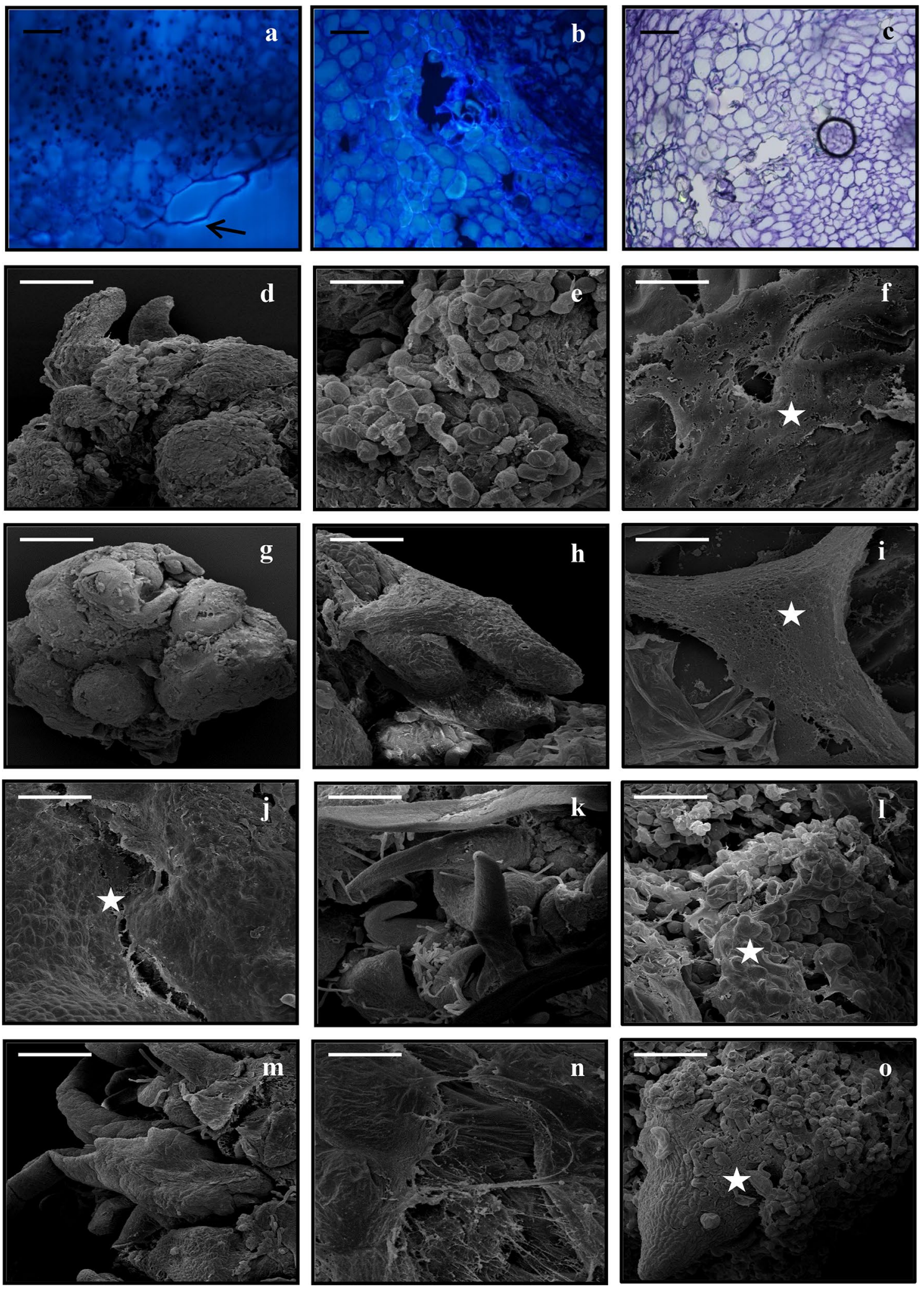

the formed adventitious shoot on the explant during callus formation. Based on the continuity of the epidermis, the presence of endogenous callus was indicated. Moreover, well-formed long vessels were observed in the place where secondary meristematic centers were formed, while wellvisible nuclei and dense cytoplasm were reported in small 
4Fig. 7 Cross-section of T. belorussicum explants: hypocotyl (a-c, $\mathbf{j}-\mathbf{k})$, cotyledon $(\mathbf{d}-\mathbf{f})$, meristem $(\mathbf{g}-\mathbf{i})$ and root $(\mathbf{m}-\mathbf{0})$ cultured on $1 / 2$ MS medium supplemented with 5.71 $\mu \mathrm{M}$ IAA, $4.54 \mu \mathrm{M}$ TDZ and $100 \mathrm{nM}$ PSK in $23 \pm 2{ }^{\circ} \mathrm{C}$ after 20 days $(\mathbf{a}-\mathbf{c})$ and 55 days $(\mathbf{d}-\mathbf{o})$ of culture from SE/PSK model/short darkness: a peripheral cells with callose in the cell wall (arrow), $\mathbf{b}$ the presence of callose in the cell wall (arrows), c control (from the light microscope), and from SE/ PSK model/long darkness: $\mathbf{d}$ organogenesis, e callus cells, $\mathbf{g}$ regenerating plantlets from endogenic callus, $\mathbf{h}$ organogenesis at various stages of development, $\mathbf{j}$ extensive amounts of ECM covering cells of explant, $\mathbf{k}$ adventitious shoots and trichomes, $\mathbf{m}$ indirect organogenesis, $\mathbf{n}$ fibrous structure of ECM, and cross-section of T. belorussicum explants: cotyledon (f), meristem (i), hypocotyl (l) and root (o) cultured on $1 / 2$ MS medium supplemented with $5.71 \mu \mathrm{M}$ IAA and $4.54 \mu \mathrm{M}$ TDZ in $23 \pm 2{ }^{\circ} \mathrm{C}$ after 45 days of culture from organogenesis model: $\mathbf{f}$ the lobe structure of ECM, $\mathbf{i}$ dense network of ECM, $\mathbf{l}$ abundant callus coated with the ECM, o regenerated plantlet growing from callus tissue of explant. a-c Staining with $0.1 \%$ toluidine blue and $0.05 \%$ aniline blue to detect the callose. Scale: $100 \mu \mathrm{m}$. d-o Scanning electron microscope. Scale: $13 \mu \mathrm{m}$ (i), $30 \mu \mathrm{m}$ (f), $180 \mu \mathrm{m}$ $(\mathbf{j}, \mathbf{l}, \mathbf{n}), 200 \mu \mathrm{m}(\mathbf{k}), 300 \mu \mathrm{m}(\mathbf{e}, \mathbf{g}), 400 \mu \mathrm{m}(\mathbf{o}), 600 \mu \mathrm{m}(\mathbf{d}), 1000 \mu \mathrm{m}$ $(\mathbf{h}, \mathbf{m})$

cells surrounding vessels. This effect indicates the meristematic nature of these cells. Such aforementioned changes observed on the cross-sections are mostly noticeable in the cotyledon's mesophyll. Still, despite many alterations, the tissue maintained compact nature and cells adhered closely to each other.

Histological analysis of the meristem explant showed the presence of secondary meristematic centers, but the continuity of tissues was not maintained. Many intercellular spaces were ECM enriched (Fig. 5d). However, continuity of epidermis was not maintained, and an exogenous callus was observed next to endogenous callus (Fig. 5e). Differences in size and shape of cells, the presence of many cytokinesis at various stages of advancement and the formation of xylogenic centers were observed (Fig. 6g). Cells stained with PAS and naphthol blue/black showed that these were viable. This was confirmed by the presence of proteins and the accumulation of starched in these cells, as well as their abundant cytoplasm. The appearance of shoots from the meristematic tissue and the presence of the first younger leaves were observed (Fig. 6c), while double staining with PAS and naphthol blue/black revealed the structure of the tissue surrounding the meristematic tissue. Herein, circular abundant meristematic and xylogenic centers, dense cytoplasm and large dividing nuclei were noted in the meristematic tissue-indicating high mitotic activity. The differentiation of callus parenchyma cells into meristematic tissues was also seen. This is a natural development.

Histologic analysis of the hypocotyl explant revealed changes in the axial roller and parenchyma of the primary cortex cells (Fig. 5g and h). Endogenous callus with large spaces between cells was also present within the primary cortex (Fig. 6h). Double staining with PAS and naphthol blue/black showed lack of epidermis continuity, abundant endogenous and exogenous callus. Moreover, meristematic and xylogenic centers had formed from subepidermal cells of callusing explant and were located inside and on the edge of the callus. The formation of adventitious shoots and somatic embryos on the explant was also noted in the meristematic centers formed in the callus (Fig. 6m). In addition, the callus was heterogenous, with different size and irregular shapes of cells. At the base of the forming adventitious shoots, new young shoots were seen to have sprouted-indicating the unsynchronized nature of indirect organogenesis.

Histological analysis of the root explant revealed a disorder in its anatomical structure, as well as large intercellular spaces, lack of epidermis continuity and presence of vascular bundles. The structure of parenchyma of the primary cortex was of compact nature. Changes in the explant's construction, the presence of meristematic centers, cell aggregates and formation of callus were observed at the later stage of explant development (Fig. 5k). Furthermore, well-developed vessels arranged in a concentric way and the explant being overgrown with callus were evident. The cross-section through the root explant also showed cytological changes characterized by different size and shapes of cells (Fig. 6i). Double staining with PAS and naphthol blue/black revealed the presence of ECM between the callus cells (Fig. 6n), while formation of adventitious shoots and the connection of explant's vascular bundle with the regenerated plant's vascular bundle were observed (Fig. 6o).

\section{The presence of callose in explant cells}

Analysis of histological samples revealed a weak presence of callose only in tissues of cotyledon and hypocotyl explants, but not in cells of root and meristem explants. In the hypocotyl explant, callose fluorescence was noted in the cell wall of peripheral cells of callus (Fig. 7a) and in the cell wall of the few parenchyma of the primary cortex cells (Fig. 7b). However, the signal of callose was uneven - this being associated with progressive deposition of callose in the cell wall.

\section{Analysis of explant organogenesis using scanning electron microscope (SEM)}

Analysis of cotyledon's explants surface indicated the presence of adventitious shoots, showed the lack of continuity of epidermis (Fig. 7d) and revealed a variety of callus cell shapes formed in some parts of the explant (Fig. 7e, l). On the surface of the adventitious shoot growing out from the meristem explant, clearly visible stomata and various callus cells were noticeable. Furthermore, the extracellular matrix with a mantle structure was seen where adventitious shoots were forming (Fig. 7f, g, i). Observation also indicated the presence of cotyledons on the surface of the explant at an advanced stage of development, with cells visible on its 
surface (Fig. 7h). Moreover, organogenesis and ECM formation on callus surface were noted on the hypocotyl explant (Fig. 7j), while single, hairline and single-celled structures were visible on the regenerated plants and explants, as were shoots at various stages of development. Apical meristem structures and single fibers at the youngest stage of development were observed (Fig. 7k). What is more, follicular callus, fibers, well visible fibrous of ECM and regenerated plants at various stages of development were observed on the root explant (Fig. 7m, n). In addition, analysis confirmed the occurrence of indirect organogenesis via callus (Fig. 7o).

\section{Discussion}

Existing world literature devoted to representatives of the genus Taraxacum is rather poor and mostly focused on their therapeutic properties (Ahmad et al. 2000; Chunga et al. 2018), developmental and embryological processes (Janas et al. 2016), and their application in in vitro culture conditions (Ermayanti and Martin 2011; Tuleja et al. 2014a).

T. belorussicum is an interesting obligatory apomictic species (Rodkiewicz et al. 1996) and was the object of rare embryological analysis (Małecka 1965, 1982; Janas et al. 2016). Preliminary studies of in vitro plant cultures (Tuleja et al. 2014a) revealed direct organogenesis without forming callus, as well as slight somatic embryogenesis on explants from immature parthenogenetic embryos. However, the obtained results did not confirm the occurrence of direct organogenesis. The same effect was also observed in other species e.g. T. officinale Weber (Chen et al. 2005). One of the possible reasons for such result can be the difference in explant origin along with their developmental stage (Kumar and Chandra 2010). The aforementioned experiments were conducted on explants derived from 2-week-old seedlings. It seems that the age of $T$. belorussicum explants plays a crucial role in SE induction and this developmental pathway is involved mostly in younger plant material (Tuleja et al. 2014a). Even the application of PSK, the peptide responsible of somatic embryogenesis induction (Igasaki et al. 2003), did not break this recalcitrance. However, slight signals of SE activity were detected in 2-week-old seedlings explants, and this was additionally confirmed by the callose presence, treated as a SE prerequisite (Dubois et al. 1989; Tao et al. 2012), as well as the first symptom of embryogenic cell potential (Fiuk and Rybczyński 2006).

The present study showed significant differences in suitability between the applied $T$. belorussicum explants. In the organogenesis model (under light condition), the best morphogenetic response was noted in hypocotyl explants, whereas, hypocotyl and meristem explants had greater response in the SE/PSK model/short darkness. The hypocotyl is employed as a promising type of explant in many studies for the induction of efficient organogenesis and somatic embryogenesis (Jach and Przywara 2000). On the other hand, cotyledon and meristem explants in the SE/PSK model/long darkness revealed better morphogenetic response than did hypocotyl and root explants after 30 and 65 days of culture under an extended period of time in dark conditions. These differences suggest that all types of explants, despite their common origin from one plant, could give various morphogenetic responses depending on the combination of growth conditions and the plant regulators used.

The high morphogenetic ability of all types of T. belorussicum explants was additionally confirmed by the noticeable presence of secondary organogenesis on the meristemregenerated plants. However, it is worth noting that under the applied in vitro conditions, the time of culture for each type of explant was not a factor limiting their viability and morphogenetic potential. This indicated the high regenerative potential of this species and the suitability of this plant for research in tissue culture field experiments.

A characteristic feature of all types of $T$. belorussicum explants employed in the applied experimental models was the relatively short time of response to the used in vitro conditions. This effect is desirable for in vitro culture of that species. It has already been demonstrated in earlier studies on T. belorussicum (Tuleja et al. 2014a) and is not a common feature among plants exposed to such conditions, e.g. Cephalotus follicularis reacts scarcely after 47 days of in vitro culture (Tuleja et al. 2014b).

The in vitro plant regenerative capacity is influenced by genetic properties and by several environmental conditions e.g. the nutrient compositions and the exposure to light. Generally, the light impact on regeneration process appears to be highly context dependent (Ikeuchi et al. 2016), light can trigger organ regeneration (Saitou et al. 1992) or inhibit root or shoot regeneration in some plants (Bellini et al. 2014). The incubation in dark conditions increased the organogenetic capacity of $T$. belorussicum hypocotyls and especially of the cotyledons. A similar effect of light was reported in Arabidopsis cotyledons (Nemeth et al. 2013).

Enhancement of in vitro plant regeneration capacity can be achieved by the use of appropriate media supplemented with PGRs. The combinations of IAA and TDZ used in these experiments were sufficient to induce organogenesis. A similar combination of the same PGRs for Cichorium intybus L. also resulted in a high level of morphogenesis (Yucesan et al. 2007). Still, data shows that the use of $1 / 2$ MS without growth regulators is sufficient for rooting Plantago asiatica (Makowczyńska and Andrzejewska-Golec 2003). However, this approach does not work in $T$. belorussicum. Therefore, the use of $1 / 2$ MS medium supplemented with IBA to achieve the effective rooting of $T$. belorussicum regenerated plants turned out necessary. This fact was confirmed by studies on Taraxacum officinale Weber (Jamshieed et al. 2010). 
The addition of PSK increased the efficiency of $T$. belorussicum organogenetic potential, as also reported from Pisum sativum and Vicia faba explants (Ochatt et al. 2018). Data showed that the use of PSK induced callus in Oryza sativa and Beta vulgaris protoplasts (Grzebelus et al. 2012), as well as cell proliferation in maize, rice, carrots or asparagus, and stimulated cell division in these plants (Yang et al. 2000). The obtained results from SE/PSK model/short darkness are associated with data on the positive impact of PSK on the morphogenesis process. In the case of T. belorussicum, the positive effect of PSK on the organogenesis process was not confirmed in SE/PSK model/long darkness. Therefore, the effect of PSK on T. belorussicum explants seems to be more favorable when the incubation time in the dark is reduced to a few days. This feature is perhaps characteristic for T. belorussicum and may be correlated with the preferences of this plant towards light conditions. Thus, the longer incubation time in the dark weakens the condition and morphogenetic potential of explants. PSK, used alone, stimulated mainly meristem, hypocotyl and root explants. In contrast, the use of PSK with auxins and cytokinins enhanced the morphogenesis process, mainly indirect organogenesis, in SE/PSK model/short darkness. This fact was confirmed by data showing that the expression of biological activity of PSK correlates with the pathway of PSK signaling via auxins and cytokinins (Matsubayashi and Sakagami 1996; Matsubayashi et al. 1999). It was observed as the formation of adventitious roots on cucumber hypocotyls (Yamakawa et al. 1998a) and adventitious buds in Antirrhinum majus (Yang et al. 1999). However, this dependency did not apply to SE/PSK model/long darkness and did not enhance morphogenesis of $T$. belorussicum.

Observation of explants showed the formation of callus after the addition of PSK. This enhanced the development of callus and significantly weakened the condition of explants. Thus, PSK which promoted the synthesis of chlorophyll in cucumber cotyledons (Yamakawa et al. 1998b), could have allowed the explants to overcome the unfavorable conditions due to the lack of light. In addition, PSK is noted to affect cell viability (Yamakawa et al. 1999) and to reduce the occurrence of albino individuals, which confirms its participation in chlorophyll synthesis through increasing photosynthesis efficiency and assimilating production (Asif et al. 2014).

Incubation with PSK in darkness affects the induction of somatic embryogenesis on hypocotyl and cotyledon explants. These results confirm the role of PSK in increasing the intensity of somatic embryogenesis of Cryptomeria japonica (Igasaki et al. 2003), Daucus carota (Kobayashi et al. 1999; Maćkowska et al. 2014) and pea (Ochatt et al. 2018). However, it seems that the induced somatic embryos of $T$. belorussicum become deformed after longer culture times, probably as a result of callus development and do not generate plantlets. In the explants, the use of different exposure periods to light and dark conditions affects the variable level of PSK which, in turn, influences morphogenesis at initial stages of cell de-differentiation, proliferation and re-differentiation. Thus, the activity of PSK was similar to the activity of plant growth and development regulators (Matsubayashi et al. 2004). Moreover, the manner of PSK function in T. belorussicum cultures probably did not differ from the function presented in our data, subject to taking into account the short incubation time in the dark.

Induction of callus formation can occur from any initial explant. For this purpose, appropriate amounts of growth regulators should be applied (Sugiyama 2000). Previous studies showed that the use of a combination of IAA and TDZ for cotyledon explants of Pelargonium rapaceum has a positive effect on callus induction and proliferation (Sukhumpinij et al. 2010). This fact was confirmed in the present study, wherein callus formation occurred more or less intensively depending on the combination of IAA, TDZ and PSK.

Histological analysis confirmed the indirect course of organogenesis and showed an increased occurrence of starch and proteins in cells of explants near the conducting elements, the effect of which indicates the energetic role of these substances, especially starch, in organogenesis (Karim et al. 2006; Pei-Lang et al. 2006). The presence of starch in the leaves of regenerated plants also revealed their photosynthetic activity, especially in SE/PSK model/short darkness. The most significant accumulation of proteins was observed in the vicinity of secondary meristematic centers, which demonstrates the high metabolic activity of these cells (Fisher 1968). In this work, the histological analysis of meristem explants revealed the occurrence of two types of organogenesis: one is based on the native development and can be assigned to the meristematic cells of the apical meristem, while the second is released through the reprogramming of the differentiated somatic cells located in the tissue surrounding the apical meristem. Both processes rely on the phenomenon of cellular plasticity, which can be defined as the ability to re-specify cell fate (Ikeuchi et al. 2016).

The presence of ECM singled out by histological analyzes and SEM on the surface of the hypocotyls and roots of $T$. belorussicum may be the result of a stress response to applied in vitro culture conditions. According to current data, ECM can be formed in response to stress factors such as tissue culture conditions or the chemical agents used to protect callus cells (Bevitori et al. 2013). It seems that the extracellular matrix (ECM) was formed to create a path for the receiving and transmitting signals that determine the recognition of cells and morphogenesis process. Until recently, ECM was considered as a marker of somatic embryogenesis in Cocos nucifera, Zea mays, Drosera sp. and Papaver sp. (Namasivayam 2007), because the cells 
acquired embryogenic competence in the presence of ECM. Currently, data suggest that the presence of ECM in in vitro culture is a specific feature of morphogenesis (PopielarskaKonieczna et al. 2013) and of morphogenetic callus formed in in vitro conditions. Of note, it may also have a protective function.

The plants obtained in in vitro cultures were in very good condition, thus they easily acclimated to the ground. The valuable result of these experiments is obtaining somatic embryos and enabling their comparative analysis with apomictic embryos.

\section{Conclusions}

Analyzes of selected Taraxacum belorussicum explants revealed that this plant showed morphogenetic abilities directed towards indirect organogenesis. Results have shown that the indirect organogenesis was not synchronized. Still, the in vitro culture conditions, through the application of IAA, TDZ and PSK factors, were sufficient for developing an efficient innovative regenerative system for each type of explants. Taking into consideration results of the study, hypocotyl explants seem to be the most promising in inducing somatic embryogenesis. In addition, observation of the culture effects revealed that callus formation is characteristic and separate for the particular type of T. belorussicum explant. Moreover, the time of T. belorussicum explant culture was not a limiting factor for their viability and morphogenetic potential. This indicates the high suitability of this species for use in in vitro experiments. Results from this study conducted on selected types of $T$. belorussicum explants also confirmed the role of PSK in the process of morphogenesis (organogenesis and somatic embryogenesis). Herein, the short incubation of T. belorussicum explants in PSK-enhanced culture, under short conditions of darkness, is most beneficial for organogenesis efficiency.

Acknowledgements The authors are grateful to Professor Jolanta Marciniuk (Institute of Biology, University of Natural Sciences and Humanities in Siedlce) for plant material (seeds) taken from the apomict Taraxacum belorussicum Val. N. Tikhom. SEM images were made in the Laboratory of Scanning Electron Microscopy for Biological and Geological Sciences, Institute of Zoology, Jagiellonian University.

Author contributions The idea of the experiments, data analyzing and writing the final version of the manuscript-MT; performing the experiments, data analyzing and writing the draft of the manuscript: AG, MG, invaluable discussions: AG, MG, MT. The authors declare that they have no conflict of interest.

Open Access This article is distributed under the terms of the Creative Commons Attribution 4.0 International License (http://creat ivecommons.org/licenses/by/4.0/), which permits unrestricted use, distribution, and reproduction in any medium, provided you give appropriate credit to the original author(s) and the source, provide a link to the Creative Commons license, and indicate if changes were made.

\section{References}

Ahmad UV, Yasmeen S, Ali Z, Khan MA, Choudhary MI, Akhtar F, Niana GA, Zahid M (2000) Taraxacin, a newguaianolide from Taraxacum wallichi. J Nat Prod 63:1010-1011

Asif M, Eudes F, Randhawa H, Amundsen E, Spaner D (2014) Phytosulfokine alpha enhances microspore embryogenesis in both triticale and wheat. Plant Cell Tissue Organ Cult 116:125-130

Bellini C, Pacurar DI, Perrone I (2014) Adventitious roots and lateral roots: similarities and differences. Annu Rev Plant Biol 65:639-666

Bevitori R, Popielarska-Konieczna M, dos Santos EM, Grossi-de-Sá MF, Petrofeza S (2013) Morpho-anatomical characterization of mature embryo-derived callus of rice (Oryza sativa L.) suitable for transformation. Protoplasma 251:545-554

Chen H, Li P, Liu J, Li XY (2005) Establishment and optimization of the regeneration system for common dandelion (Taraxacum officinale Weber). Sheng Wu Gong Cheng XueBao 2:244-249

Chunga HJ, Nohd Y, Kime MS, Janga A, Leea ChE, Myung SCh (2018) Steroidogenic effects of Taraxacum officinale extract on the levels of steroidogenic enzymes in mouse Leydig cells. Anim Cells Syst 22:407-414

Dubois T, Guedira M, Dubois J, Vasseur J (1989) Direct somatic embryogenesis in roots of Cichorium: is callose an early marker? Ann Bot 65:539-545

Ebida AIA, Hu C (1993) In vitro morphogenetic responses and plant regeneration from pepper (Capsicum annuum L. cv. Early California Wonder) seedling explants. Plant Cell Rep 13:107-110

Ellinger D, Voigt ChA (2014) Callose biosynthesis in Arabidopsis with a focus on pathogen response: what we have learned within the last decade. Ann Bot 114:1-10

Ermayanti TM, Martin AF (2011) In vitro growth response of Taraxacum officinale Weber ex F.H. Wigg regenerated from different type of explants. Ann Bogor 1:7-13

Erofeeva EA (2014) Dependence of dandelion (Taraxacum officinale Wigg.) seed reproduction indices on intensity of motor traffic pollution. Dose-Response 12:540-550

Fisher DB (1968) Protein staining of ribboned epon sections for light microscopy. Histochemie 16:92-96

Fiuk A, Rybczyński JJ (2006) Wykorzystanie metod współczesnej analizy materiału roślinnego w badaniach somatycznej embriogenezy Gentiana kurroo (Royle). Biotechnologia 4:95-106

Grzebelus E, Szklarczyk M, Greń J, Śniegowska K, Jopek M, Kacińska I, Mrożek K (2012) Phytosulfokine stimulates cel divisions in sugar beet (Beta vulgaris L.) mesophyll protoplast cultures. Plant Growth Regul 67:93-100

Hand ML, Koltunow AMG (2014) The genetic control of apomixis: asexual seed formation. Genetics 197:441-450

$\mathrm{Hu}$ Ch, Kitts DD (2003) Antioxidant, prooxidant, and cytotoxic activities of solvent-fractionated dandelion (Taraxacum officinale) flower extracts in vitro. J Agric Food Chem 51:301-310

Huang X, Chen J, Bao Y, Liu L, Jiang H, An X, Dai L, Wang B, Peng D (2014) Transcript profiling reveals auxin and cytokinin signaling pathways and transcription regulation during in vitro organogenesis of Ramie (Boehmerianivea L. Gaud). PLoS ONE 9:1-24

Igasaki T, Akashi N, Ujino-Ihara T, Matsubayashi Y, Sakagami Y, Shinohara K (2003) Phytosulfokine stimulates somatic embryogenesis in Cryptomeria japonica. Plant Cell Physiol 44:1412-1416 
Ikeuchi M, Ogawa Y, Iwase A, Sugimoto K (2016) Plant regeneration: cellular origins and molecular mechanisms. Development 143:1442-1451

Isah T (2015) Adjustments to in vitro culture conditions and associated anomalies in plants. Acta Biol Crac Ser Bot 57:9-28

Jach M, Przywara L (2000) Somatic embryogenesis and organogenesis induced in immature zygotic embryos of selected sunflower Helianthus annuus L. genotypes. Acta Biol Crac Ser Bot 2:83-86

Jamshieed S, Das S, Sharma MP, Srivastava PS (2010) Difference in in vitro response and esculin content in two population of Taraxacum officinale Weber. Physiol Mol Biol Plants 16:353-359

Janas A, Musiał K, Kościńska-Pająk M, Marciniuk P (2016) Insights into developmental processes in anthers, ovaries, and ovules of Taraxacum belorussicum (Asteraceae-Cichorioideae) DIC optics. Plant Syst Evol 302:617-628

Jasrai TY, Thaker KN, D'Souza CM (2003) In vitro propagation of Euphorbia pulcherrima Willd. through somatic embryogenesis. Plant Tissue Cult 13:31-36

Karim MZ, Yokota S, Azad MAK, Eizawa J, Ihiguri F, Iizuka K, Yahara S, Yoshizawa N (2006) Relationship between starch accumulation and organ development at the different growth stages of callus in Kihada (Phellodendron amurense Rupr.). Plant Biotechnol 23:239-245

Kobayashi T, Eun ChH, Hanai H, Matsubayashi Y, Sakagami Y, Kamada H (1999) Phytosulphokine- $\alpha$, a peptidyl plant growth factor, stimulates somatic embryogenesis in carrot. J Exp Bot 50:1123-1128

Koltunow AM (1993) Apomixis: embryo sacs and embryos formed without meiosis or fertilization in ovules. Plant Cell 5:1425-1437

Kumar S, Chandra A (2010) In vitro plantlet regeneration in Stylosanthes spp via callus induction from cotyledonary and hypocotyl explants. Natl Acad Sci Lett 33:289-297

Kuo HL, Chen JT, Chang WCh (2005) Efficient plant regeneration through direct somatic embryogenesis from leaf explants of Phalaenopsis 'Little Steve'. In Vitro Cell Dev Biol-Plant 41:453-456

Lorbiecke R, Steffens M, Tomm JM, Scholten S, Von Wiegen P, Kranz E, Wienand U, Sauter M (2005) Phytosulphokine gene regulation during maize (Zea mays L.) reproduction. J Exp Bot 56:1805-1819

Maćkowska K, Jarosz A, Grzebelus E (2014) Plant regeneration from leaf-derived protoplasts within the Daucus genus: effect of different conditions in alginate embedding and phytosulfokine application. Plant Cell Tissue Organ Cult 117:241-252

Makowczyńska J, Andrzejewska-Golec E (2003) Micropropagation of Plantago asiatica L. through culture of shoot-tips. Acta Soc Bot Pol 72:191-194

Małecka J (1965) Embryological studies in Taraxacum palustre. Acta Biologica Cracoviensia Series Botanica 8:223-235

Małecka J (1982) Further embryological studies in the genus Taraxacum L. Acta Biol Crac Ser Bot 24:143-157

Marciniuk J, Rerak J, Grabowska-Joachimiak A, Jastrząb I, Musiał K, Joachimiak AJ (2010) Chromosome numbers and stomatal cell length in Taraxacum sect. Palustria from Poland. Acta Biol Crac Ser Bot 52:117-121

Matsubayashi Y, Sakagami Y (1996) Phytosulfokine, sulfated peptides that induce the proliferation of single mesophyll cells of Asparagus officinalis L. Proc Natl Acad Sci USA 93:7623-7627

Matsubayashi Y, Morita A, Matsunaga E, Furuya A, Hanai N, Sakagami Y (1999) Physiological relationships between auxin, cytokinin, and a peptide growth factor, phytosulfokine- $\alpha$, in stimulation of asparagus cell proliferation. Planta 207:559-565

Matsubayashi Y, Goto T, Sakagami Y (2004) Chemical nursing: phytosulfokine improves genetic transformation efficiency by promoting the proliferation of surviving cells on selective media. Plant Cell Regul 23:155-158
Murashige T, Skoog F (1962) A revised medium for rapid growth and bioassays with tobacco tissue cultures. Physiol Plant 15:437-497

Namasivayam P (2007) Acquisition of embryogenic competence during somatic embryogenesis. Plant Cell Tissue Organ Cult 90:1-8

Nemeth B, Dinka SJ, Chatfield SP, Morris A, English J, Lewis D, Oro R, Raizada MN (2013) The shoot regeneration capacity of excised Arabidopsis cotyledons is established during the initial hours after injury and is modulated by a complex genetic network of light signalling. Plant Cell Environ 36:68-86

Nic-Can GI, Galaz-Ávalos RM, De-la-Peña C, Alcazar-Magaña A, Wróbel K, Loyola-Vargas VM (2015) Somatic Embryogenesis: identified factors that lead to embryogenic repression. A case of species of the same genus. PLoS ONE 10:1-21

Noyes RD (2007) Apomixis in the Asteraceae: diamonds in the rough. Funct Plant Sci Biotechnol 1:207-222

Ochatt S, Conreux C, Mcolo RM, Despierre G, Magnin-Robert J-B, Raffiot B (2018) Phytosulfokine-alpha, an enhancer of in vitro regeneration competence in recalcitrant legumes. Plant Cell Tissue Organ Cult 135:189-201

Pei-Lang AT, Mohamed AMD, Karim AA (2006) Sago starch and associated components in palms of different growth stages. Carbohyd Polym 63:283-286

Popielarska-Konieczna M, Kozieradzka-Kiszkurno M, Tuleja M, Ślesak H, Kapusta P, Marcińska I, Bohdanowicz J (2013) Genotype-dependent efficiency of endosperm development in culture of selected cereals: histological and ultrastructural studies. Protoplasma 250:361-369

Rodkiewicz B, Śnieżko R, Fyk B, Niewęgłowska B, Tchórzewska D (1996) Embriologia Angiospermae rozwojowa i eksperymentalna. Wydaw Uniw Marii Curie-Skłodowskiej 2:213-223

Saitou T, Kamada H, Harada H (1992) Light requirement for shoot regeneration in horseradish hairy roots. Plant Physiol 99:1336-1341

Sugiyama M (2000) Genetic analysis of plant morphogenesis in vitro. Int Rev Cytol 196:67-84

Sukhumpinij P, Kakihara F, Kato M (2010) In vitro regeneration from mature leaf explants of Pelargonium rapaceum (L.). Sci Hortic 126:385-389

Tao L, Yang Y, Wang Q, You X (2012) Callose deposition is required for somatic embryogenesis in plasmolyzed Eleutherococcus senticosus zygotic embryos. Int J Mol Sci 13:14115-14126

Tikhomirov V (2003) Generis Taraxacum Wigg. (Asteraceae) species nova e Belorussia. Nov Sist Vysshikh Rastenii 35:207-210

Tuleja M, Chmielowska A, Płachno BJ (2014a) The preliminary attempts of in in vitro regeneration from petioles of recalcitrant species of Cephalotus follicularis Labill. Mod Phytomorphol 6:37-38

Tuleja M, Ślesak H, Musiał K, Joachimiak AJ (2014b) Molecular, histological and embryological analysis of regenerants obtained during in vitro culture of immature embryos of apomictic Taraxacum belorussicum Val. N. Tikhom. Mod Phytomorphol 6:33-35

Williams EG, Maheswaran G (1986) Somatic embryogenesis: factors influencing coordinated behaviour of cells as an embryogenic group. Ann Bot 57:443-462

Woźny A, Przybył K (2004) Komórki roślinne w warunkach stresu. Komórki in vitro. Wydaw Naukowe UAM 2(29-50):72-91

Yamakawa S, Matsubayashi Y, Sakagami Y, Kamada H, Satoh S (1998a) Promotion by a peptidyl growth factor, phytosulfokine, of chlorophyll formation in etiolated cotyledon of cucumber. Biosci Biotechnol Biochem 62:2441-2443

Yamakawa S, Sakuta Ch, Matsubayashi Y, Sakagami Y, Kamada H, Satoh S (1998b) The promotive effects of a peptidyl plant growth factor, phytosulfokine- $\alpha$, on the formation of adventitious roots and expression of a gene for a root-specific cystatin in cucumber hypocotyls. J Plant Res 111:453-458 
Yamakawa S, Matsubayashi Y, Sakagami Y, Kamada H, Satoh S (1999) Promotive effects of the peptidyl plant growth factor, phytosulfokine- $\alpha$, on the growth and chlorophyll content of Arabidopsis seedlings under high night-time temperature conditions. Biosci Biotechnol Biochem 63:2240-2243

Yang H, Matsubayashi Y, Nakamura K, Sakagami Y (1999) Oryza sativa PSK gene encodes a precursor of phytosulfokine-alpha, a sulfated peptide growth factor found in plants. Proc Natl Acad Sci USA 96:13560-13565

Yang H, Matsubayashi Y, Hanai H, Sakagami Y (2000) Phytosulfokine- $\alpha$, a peptide growth factor found in higher plants: its structure, functions, precursor and receptors. Plant Cell Physiol $41: 825-830$
Yucesan B, Turker AU, Gurel E (2007) TDZ-induced high frequency plant regeneration through multiple shoot formation in witloof chicory (Cichorium intybusb L.). Plant Cell Tissue Organ Cult 91:243-250

Publisher's Note Springer Nature remains neutral with regard to jurisdictional claims in published maps and institutional affiliations. 